\title{
Monitoring and managing large deformation pit slope instabilities at a British Columbia copper mine
}

\author{
G Dick BGC Engineering Inc., Canada
}

S Nunoo Gibraltar Mines Ltd., Canada

S Smith Gibraltar Mines Ltd., Canada

W Newcomen BGC Engineering Inc., Canada

D Kinakin BGC Engineering Inc., Canada

I Stilwell BGC Engineering Inc., Canada

J Danielson BGC Engineering Inc., Canada

\begin{abstract}
Pit slopes exhibiting large deformations due to weak and complex fault zones within an otherwise good quality rock mass are characteristic of an open pit mine in British Columbia, Canada. Following the introduction of a database with 26 pit slope instabilities, the paper describes one of the instabilities, which exhibited over $70 \mathrm{~m}$ of cumulative deformation over the course of one year without collapsing. Ground-based slope stability radar and prisms surveyed by a robotic total station continuously monitored the pit slope deformation rates as the instability area experienced acceleration events lasting several days as mining of the high slope progressed towards its final height of $320 \mathrm{~m}$. Integrating ground-based radar and surface deformation monitoring with drone photogrammetry was instrumental in understanding the complex failure mechanism and successfully managing this instability.
\end{abstract}

Keywords: pit slope deformation monitoring, slope stability radar, slope instability database

\section{Introduction}

Large slope deformations are characteristic of an open pit copper porphyry mine in British Columbia, Canada. The rock mass is comprised of generally strong tonalite with a variable fabric, ranging from homogeneous to strongly foliated. The presence of faults, which provide the main geotechnical controls on the design slope angles, occasionally results in high pit slope deformations in an otherwise good quality rock mass. This paper has two parts; first a slope instability database of 26 cases developed at the mine is presented; and second the successful management of one of these instabilities over a period of one year, where over $70 \mathrm{~m}$ of deformation was exhibited without catastrophic collapse of the slope.

A comprehensive slope monitoring programme, coupled with timely review and appropriate interpretation of the measured movement data, is an important slope stability management tool. The geotechnical engineering team at the mine consists of a partnership between the onsite mine engineering staff (the 'implementors') and consultant geotechnical engineers and engineering geologists (the 'designers') (Newcomen \& Dick 2015). The geotechnical engineering team implements a regular slope monitoring programme, which has evolved over the past 15 years and has documented numerous instabilities that have occurred over that period. Surface monitoring instrumentation has evolved from manual weekly theodolite surveys to continuous monitoring via ground-based radar and robotic total station monitoring systems. The slope monitoring programme implemented by the geotechnical engineering team also involves visual inspections. The monitoring techniques are consistent with those typically applied at open pit porphyry copper mines in British Columbia (Nunoo et al. 2015). 


\section{Slope instability database}

The mine consists of two active open pits (Granite and Pollyanna) and two inactive open pits (Gib East and Gib West). The stability of the pit slopes is strongly influenced by the presence of unfavourably oriented geologic structures, poor rock mass quality (typically associated with major structures), and the presence of shear zones and foliation in the rock mass fabric. Significant effort is put into mapping and defining faults by the geotechnical engineering team as they are the critical control on pit wall stability. The major structures model has been developed using surface (mapping and photogrammetry) and sub-surface (oriented core and televiewer) data, as well as specific energy data collected during blasthole drilling (Danielson et al. 2017).

Twenty-six (26) instabilities recorded at the mine, from 2006 to present, were compiled and are presented in Figure 1 in terms of their affected slope height and overall slope angle when the instability was initially observed. A similar slope angle versus slope height databases was developed by Sjöberg (2000) and has been used by the geotechnical engineering team as an empirical tool to calibrate slope designs in areas where specific major geologic structures are anticipated. The presented database is limited to inter-ramp and overall slope scale instabilities. These instabilities have been recorded by the geotechnical engineering team as a part of the formal documentation procedure. This paper focuses on instabilities that have occurred in Granite Pit, which has been the primary area of mining since 2006. The term instability in this context is defined as an area where significant irreversible deformation results in the slope no longer being able to meet its design purpose (Dick et al. 2015). This is typically associated with deformation rates higher than the 'background' level associated with initial response and primary creep (Mercer 2006).

\begin{tabular}{|c|c|}
\hline$\square$ 10 FAULT & $\nabla 13$ FAULT \\
\hline $\bar{\triangle}$ EAST BOUNDARY FAULT & $\triangle$ BROWN FAULT \\
\hline FOLIATION & $\{$ CREEK FAULT \\
\hline$\diamond 9$ FAULT/8 FAULT & $\diamond$ UNIDENTIFIED \\
\hline
\end{tabular}

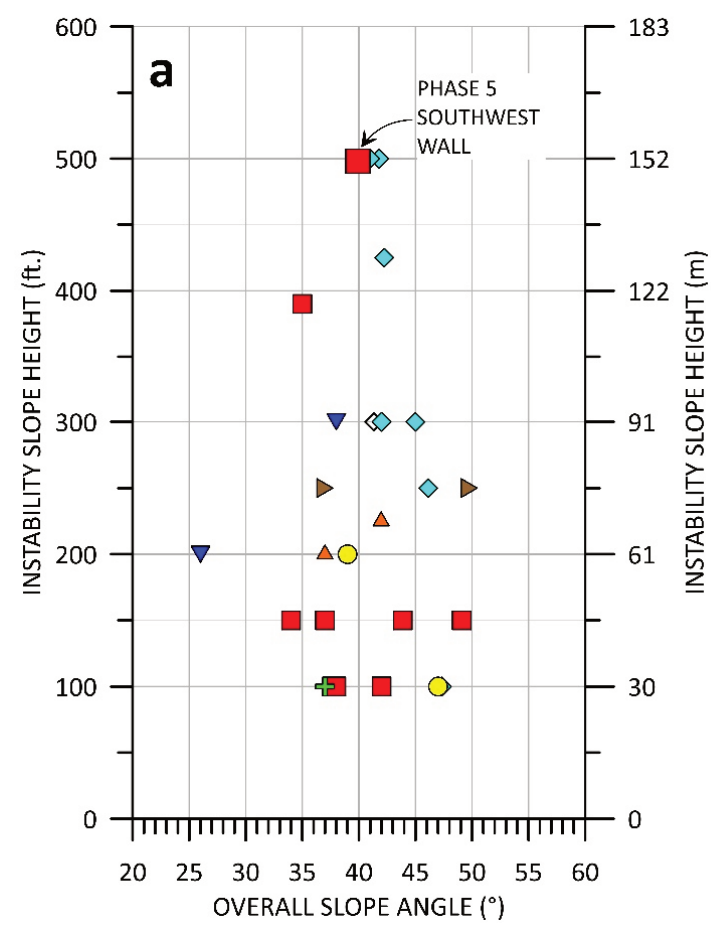

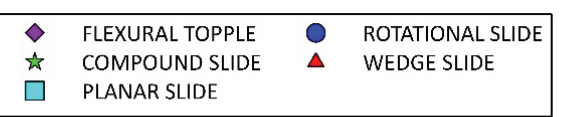

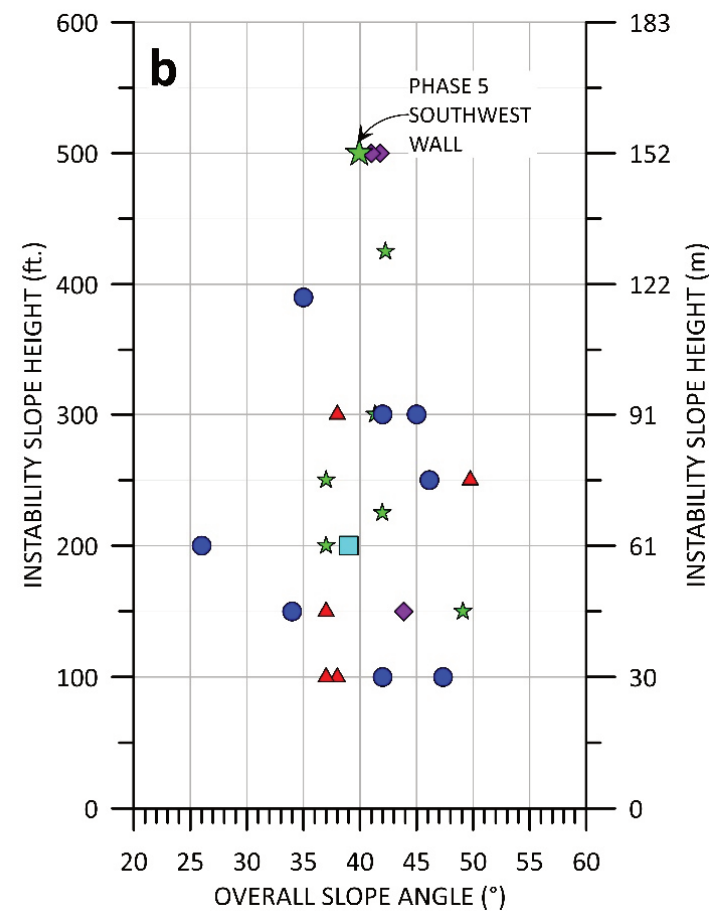

Figure 1 Empirical slope height versus slope angle relationships for instabilities in Granite Pit sorted by: (a) Major geologic structure; and (b) Interpreted failure mode

Figure 1a illustrates the slope height and slope angle relationship by associated major geologic structures within the geological model associated with the instability. 10 Fault is the most influential geological structure in the Granite Pit and has contributed to eight of the instabilities presented in the database. 10 Fault is a large, low-angle (dip of 20 to $30^{\circ}$ ) geologic structure with a thick gouge core and a damage zone wider than $30 \mathrm{~m}$ (Mostaghimi \& Kennedy 2015) in some locations. 
Multi-bench instabilities have occurred in the Granite Pit with failure modes ranging from simple large-scale wedge, planar, and toppling to more complex failure modes. Figure $1 \mathrm{~b}$ illustrates the slope height and slope angle relationship based on the interpreted instability mechanism following Hungr et al. (2014). The term 'compound slide' has been assigned to instabilities demonstrating more than one type of failure mechanism and 'rotational slide' has been assigned to instabilities that were interpreted to occur in a weak rock mass.

The following can be inferred from the database presented in Figure 1:

- 10 Fault was associated with the greatest number of the instabilities and the widest range of failure modes, occurring in-pit slopes with overall angles as low as $33^{\circ}$.

- Instabilities have occurred for a wide range of slope heights ( $30 \mathrm{~m}$ to $150 \mathrm{~m}$ ) and slope angles ( $26^{\circ}$ to $\left.50^{\circ}\right)$.

- All but one of the instabilities occurred for overall slope angles greater than $33^{\circ}$, suggesting that pit walls in Granite Pit that encounter major structures do not perform well when slopes steeper than this are excavated. Extensive slope monitoring will generally be required.

- The instability with an overall slope angle of $26^{\circ}$, occurred in a slope with waste rock overlying weak and faulted bedrock.

Daylighting of major geological structures and mining in proximity to basal shear surfaces are the most commonly observed precursors to instability (Danielson 2018). Blasting in the vicinity of existing instabilities is also observed to influence deformation rates. High porewater pressures have been suspected in several of the instabilities; however, groundwater monitoring data are sparse and direct correlations between porewater pressures and displacements cannot generally be confirmed. Slope depressurisation programs, consisting of vertical pumping wells and horizontal drain holes (HDHs), have been implemented by the geotechnical engineering team to improve the overall wall stability. HDH programs typically target major geological structures implicated in the instabilities. Major structures at the mine are typically groundwater barriers, resulting in the compartmentalisation of porewater pressures within the rock mass, making it difficult to dewater.

One of the instabilities shown in Figure 1 occurred during the final (Phase 5) pushback of the Southwest Wall of the Granite Pit. This instability experienced the largest amount of deformation of all instabilities in the Granite Pit and is further described.

\section{Phase 5 Southwest Wall instability}

An instability began to develop in the Southwest Wall of the Granite Pit in mid-2016 while excavating the final (Phase 5) pushback and started to affect operational efficiency at the mine in early 2017. Surface deformations were monitored using survey prisms and a robotic total station, a GroundProbe ground-based slope stability radar (SSR), and photogrammetry data collected with an unmanned aerial vehicle (UAV). Deformation rates measured from the SSR in the main area of the instability ranged from $25 \mathrm{~mm} /$ day in late 2016 to over $900 \mathrm{~mm} /$ day in mid-2017. The large deformations are interpreted to be from shearing and squeezing in the highly disturbed rock mass associated with the 10 Fault zone, initiating a combination of toppling and wedge failure above 10 Fault.

The volume of the disturbed mass of the main area of instability is estimated to be on the order of $1.1 \mathrm{Mt}$. Mining was increasingly disrupted by shutdowns to allow slope deformation rates to abate. Once mining of the El. $975 \mathrm{~m}$ bench was completed, a step-in was implemented to mitigate the instability and facilitate mining to the ultimate pit bottom at El. $930 \mathrm{~m}$.

\subsection{Background}

The Southwest Wall of the Granite Pit has a history of instability. Two large instabilities previously developed while mining the Phase 4 Southwest Wall: a toppling instability associated with 8 Fault, 9 Fault and several other minor faults dipping steeply into the pit slope, and a consistent ravelling instability caused by the 
exposure of the poor-quality rock mass within the 10 Fault zone lower down the slope. The maximum Phase 4 Southwest Wall slope height above 10 Fault was approximately $180 \mathrm{~m}$. Experience from managing the instabilities that developed during the mining of the Phase 4 Southwest Wall factored into the design for the Phase 5 Southwest Wall slope design, supported by 2-dimensional limit equilibrium and finite element slope stability modelling, resulted in a reduction of the design inter-ramp angle for the Phase 5 Southwest Wall to $38^{\circ}$ from $40^{\circ}$. It was also recognised that the Phase 5 wall was the final wall, and that mitigation measures such as unloading were not as easily implemented or desirable at that stage of mining. Thus, a slightly shallower inter-ramp angle was considered to be prudent.

When mining of the Phase 5 pushback was nearly complete, a design optimisation to mine out a ramp left on the final wall was proposed, effectively resulting in a $335 \mathrm{~m}$ high inter-ramp slope from the pit crest to the proposed pit bottom. Slope stability analyses of this configuration indicated an increasing potential for instability as mining progressed and increasingly higher pit slopes were exposed above 10 Fault (i.e. model convergence became increasingly difficult as mining approached the vicinity of 10 Fault). The risk of instability was accepted by the mine due to the high ore grades at the toe of the slope and confidence that a 'mine and monitor approach' could be implemented in anticipation of substantial slope movements.

\subsection{Geotechnical model}

The failure mechanism of the Phase 5 Southwest Wall instability is still not fully understood; however, it has been interpreted to be a complex toppling instability due to the presence of at least three major faults dipping steeply into and striking subparallel to the pit slope. A non-daylighting wedge created by the NFG Fault (which was not recognised during Phase 4 mining) and NF6 Fault allowed mobilisation of the upper slope, while limiting the extent of failure retrogression behind the slope crest. Toppling along 8 Fault caused increased displacement and down-dropping of the upper slope. The highly disturbed rock mass within the 10 Fault zone experienced squeezing and shearing, possibly providing a basal shear plane for the toppling instability.

The Southwest Wall instability is divided into five main 'zones' based on the geological model and observed slope deformation trends. Figure 2 shows a photograph of the slope and the interpreted major faults. Figure 3 shows a cross-section through the Main Instability and Lower 10 Fault Zone.

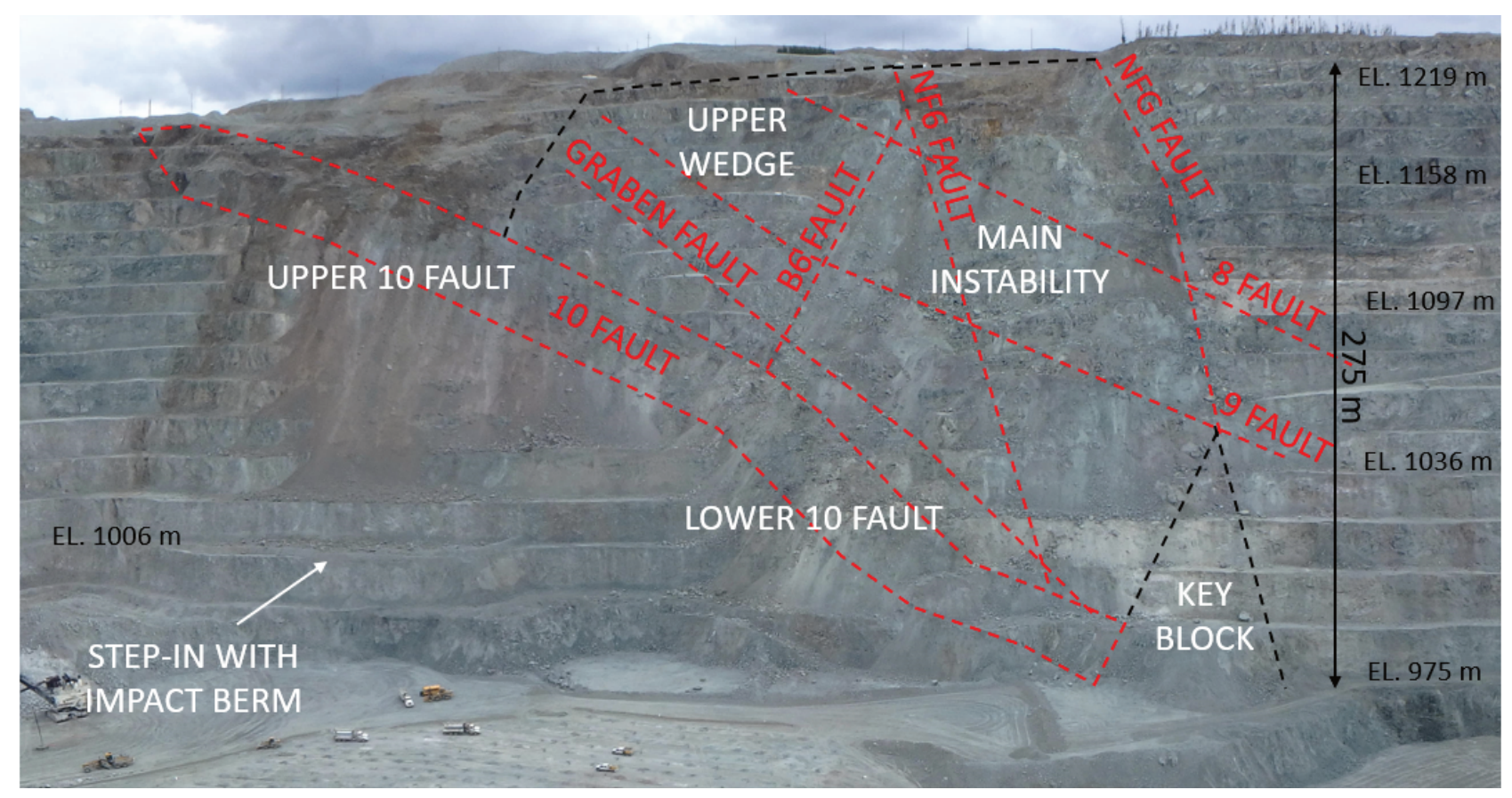

Figure 2 View of Southwest Wall instability and defined instability zones on May 11, 2017 


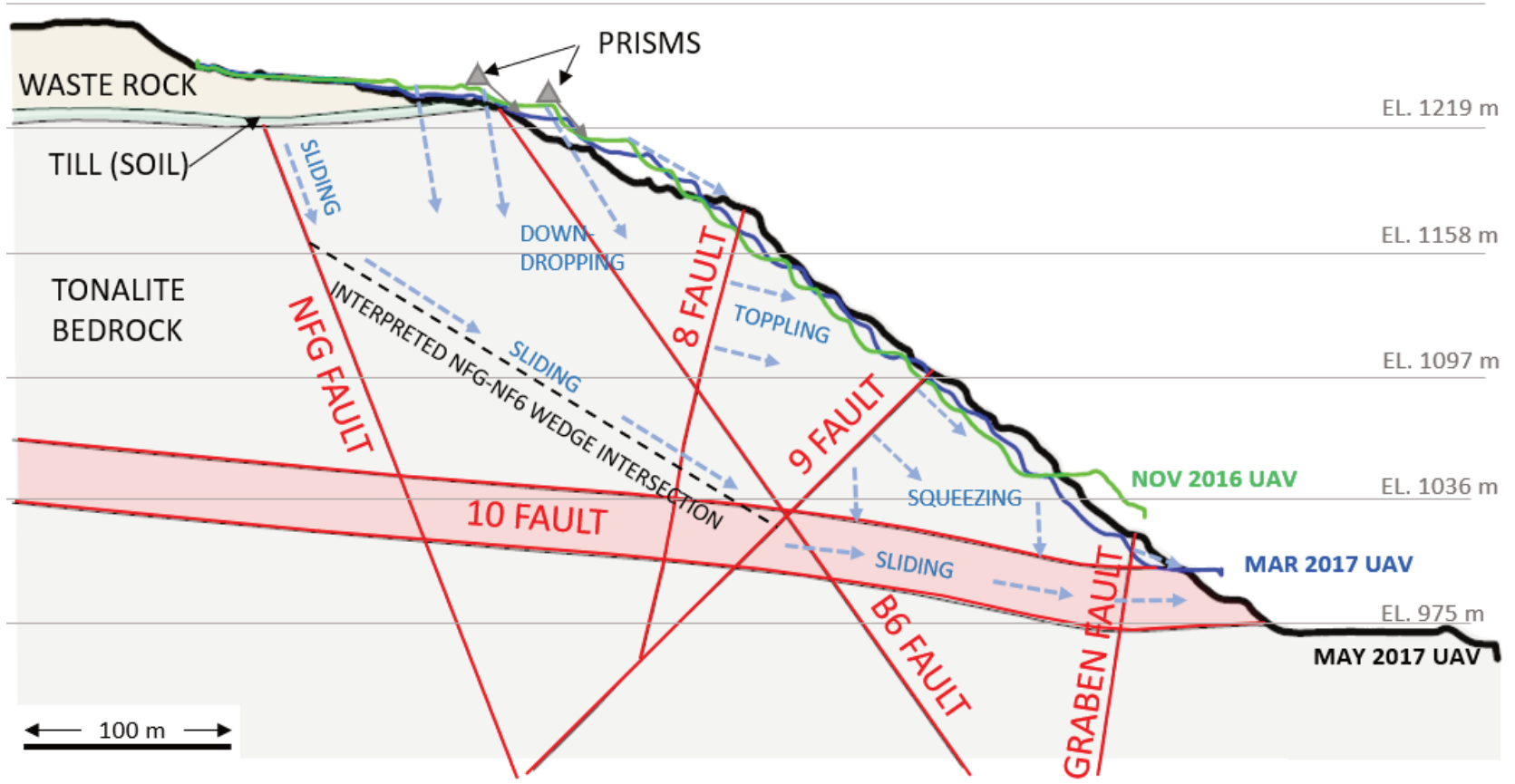

Figure 3 Cross-section through the Main Instability and Lower 10 Fault Zones illustrating the interpreted failure mechanism

Figure 4 shows the SSR data and major fault intersections overlain on a digital terrain model (DTM) generated from UAV photogrammetry. Change detection between DTMs generated by UAV photogrammetry was used to interpret the spatial distribution of the deformations associated with the instability. Five main areas of the instability were defined and are described as follows:

- The Upper and Lower 10 Fault Zones are soft and continuously deform (squeeze), resulting in filled benches and rockfall hazards. These zones are highly sensitive to mining at the toe of the slope.

- The Main Instability Zone is also associated with high deformation rates, with toppling occurring on 8 Fault, 9 Fault and Graben Fault in the mid-portion of the slope and a non-daylighting wedge formed by the NF6 and NFG faults in the upper portion of the slope. The NFG Fault appears to be truncated by 9 Fault, and, as a result, the movement associated with the wedge does not extend to the toe of the slope.

- The Upper Wedge Zone is relatively stable and bounded by 10 Fault and B6 Fault.

- The Key Block Zone is defined by the rock mass between the lower extent of the NFG Fault and 10 Fault, leaving a block of relatively 'stable' rock in the toe of the instability. The western extent of the Key Block zone (i.e. the right side on Figure 4) is not defined by a sharp contrast in deformation, suggesting that side of the failure is not fault controlled. 


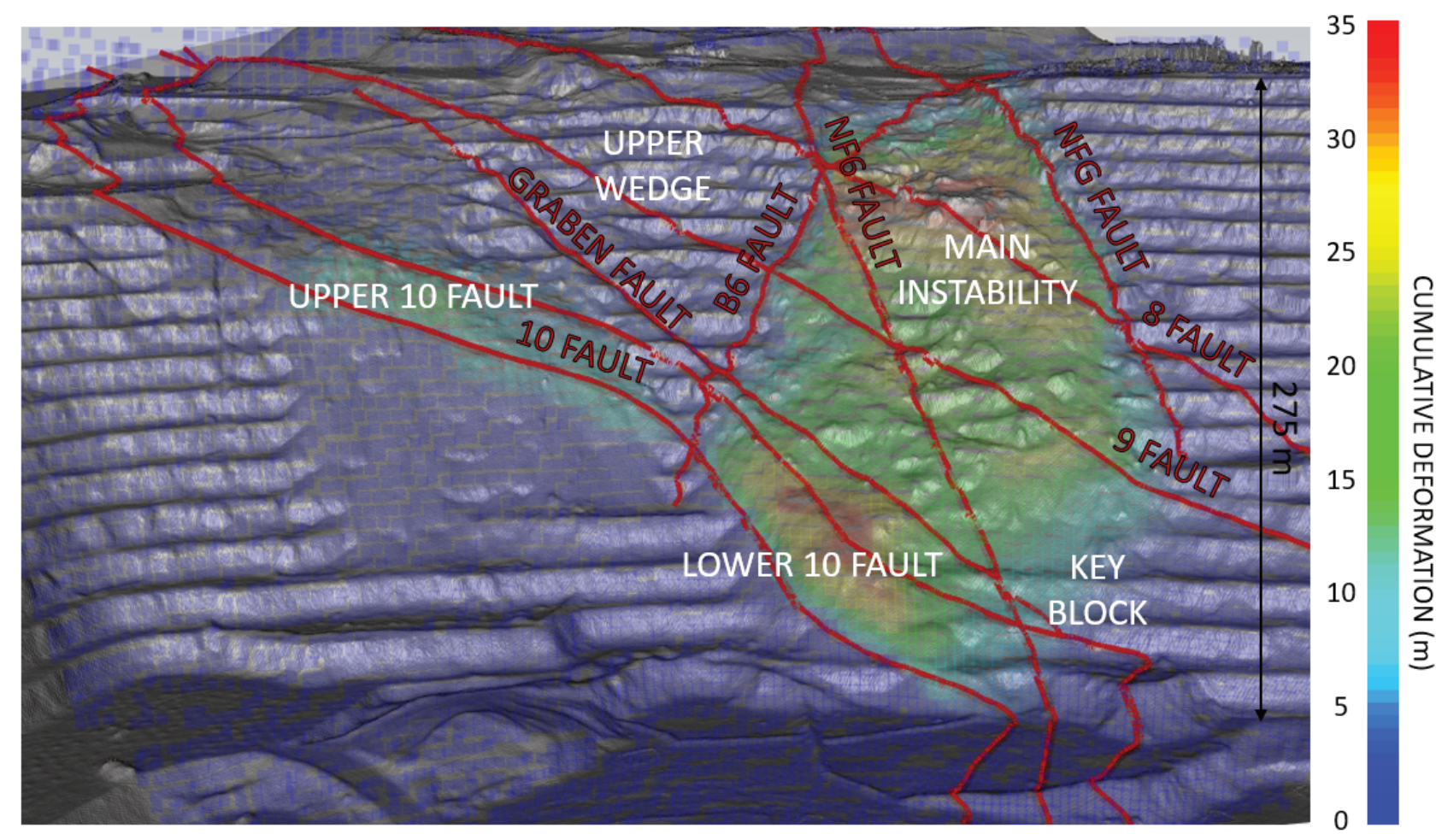

Figure 4 Slope stability radar cumulative deformation measurements between March 15 and May 11, 2017, overlain on the May 1, 2019 DTM with geological faults

The effects of porewater pressure on the instability is uncertain as there were no piezometers monitoring the Southwest Wall of the Granite Pit during the early development of the instability. A nest of three vibrating wire piezometers (VWPs) was installed near the toe of the slope in May 2017 to monitor porewater pressures in the Southwest Wall adjacent to the instability area (discussed further in Section 3.5).

\subsection{Slope deformation characteristics}

The time-deformation histories of the five instability zones indicated in Figures 2 and 4 were monitored on a continuous basis as mining of the Phase 5 Southwest Wall progressed. Figure 5 shows the time-deformation characteristics of the five areas from the SSR between October 7, 2016 and November 1, 2017. The deformation rate thresholds shown in Figure 5 were defined in a Safe Work Plan (SWP) and are discussed in detail in Section 3.4. The plotted time-deformation data were defined by areas approximately $30 \mathrm{~m} \times 30 \mathrm{~m}$ (approximately two bench heights), as shown in Figure 6. The deformation is averaged over the selected pixels, providing a smoother, less noisy trend then selecting a single pixel. Deformation rates are shown using a 12-hour time window average to reduce SSR data noise to better visualise long-term data trends (Dick et al. 2015). Time-averaged deformation rate magnitudes are less than the actual incremental deformation rates between SSR scans. 


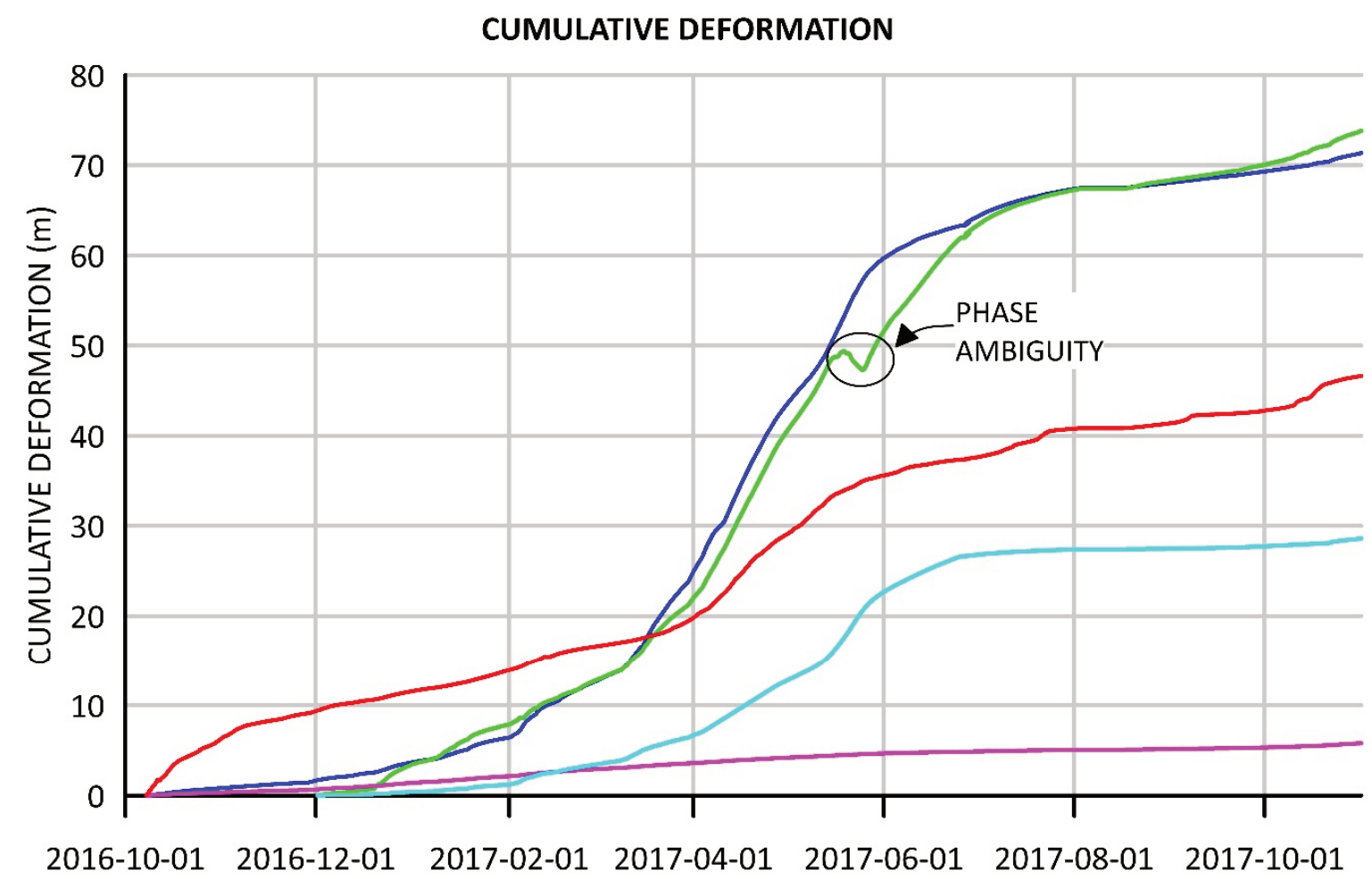

— UPPER SLOPE — LOWER 10 FAULT — UPPER WEDGE — KEY BLOCK — UPPER 10 FAULT

DEFORMATION RATE AVERAGED OVER 12 HOURS

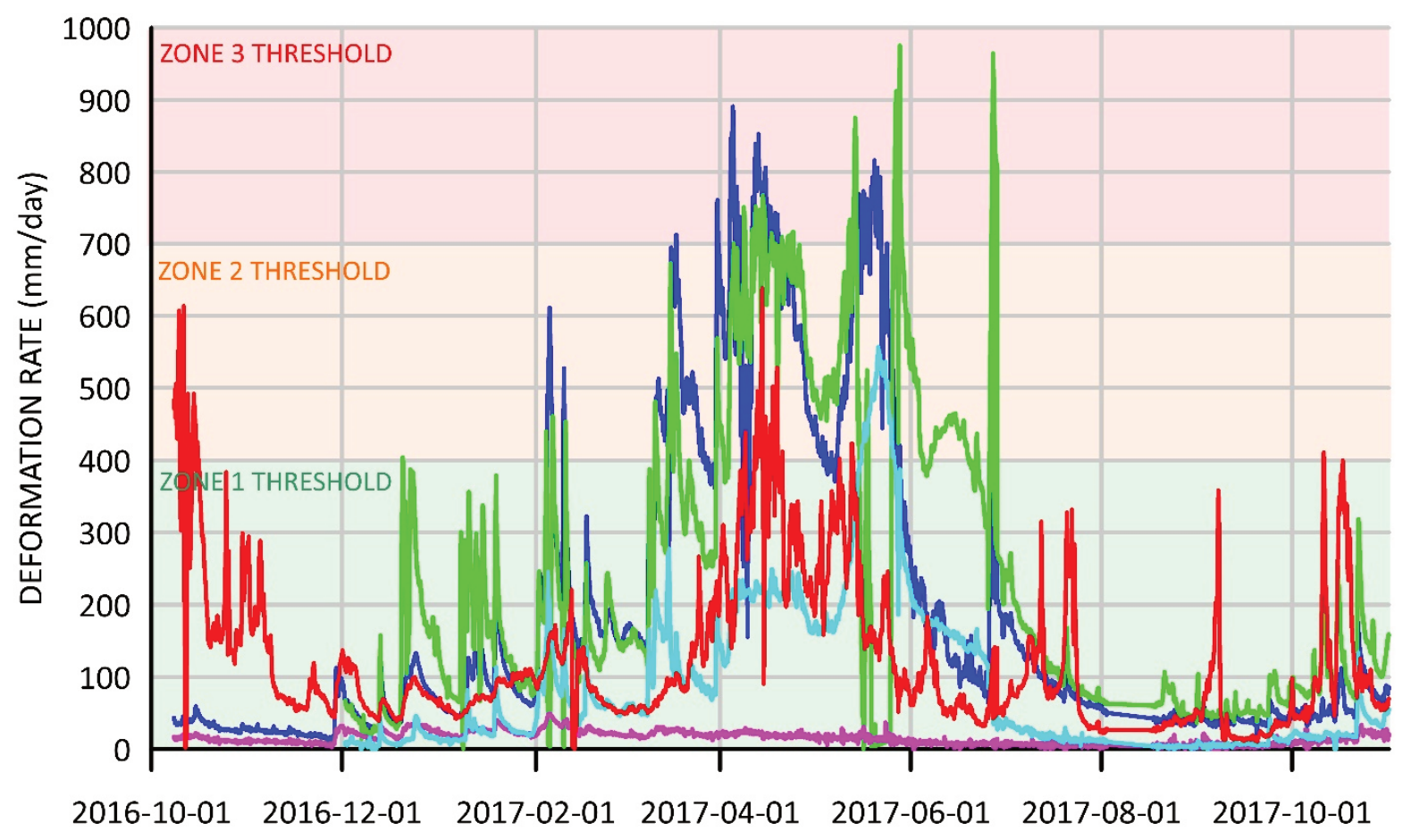

Figure 5 Slope stability radar cumulative deformation and deformation rate trends for the five monitoring areas between October 7, 2016 and November 1, 2017 


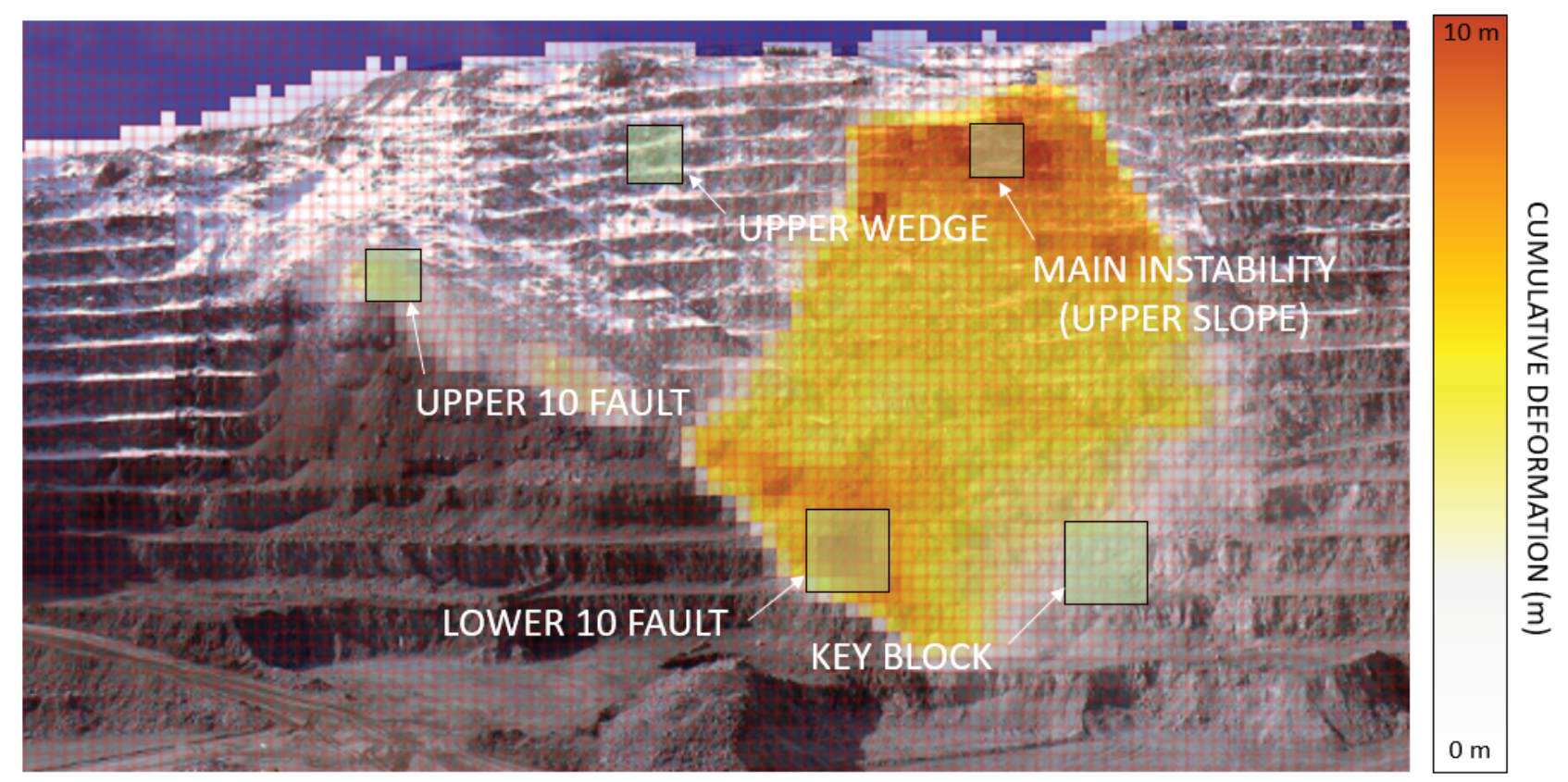

Figure 6 Slope monitoring areas overlain on the slope stability radar cumulative deformation measurements from March 15, 2017 to April 5, 2017

The following observations can be inferred from the time-deformation trends shown on Figure 5:

- Accelerating displacement of the Main Instability (Upper Slope) commenced at the beginning of December 2016 while the Lower 10 Fault acceleration began approximately three weeks later.

- An increase in acceleration trends of the Main Instability commenced early February 2017. The Key Block deformation rates remained relatively low but constant until February 2017, when an acceleration trend began to develop.

- The largest deformations occurred at the onset of mining the El. $991 \mathrm{~m}$ and the El. $975 \mathrm{~m}$ benches in March and April 2017 as 10 Fault became more exposed on the pit wall.

- The instability was strongly reactive to mining events (blasting and digging at the toe).

- The slope displaced enough between sequential radar scans on May 20, 2017, that a radar phase ambiguity occurred in the Lower 10 Fault Zone.

- The Key Block was an important component of the instability, providing a buttressing effect and limiting the potential for catastrophic failure, despite total deformations of over $25 \mathrm{~m}$ in this portion of the slope.

Newcomen \& Dick (2015) present a strain-based approached for failure prediction, where 'strain' is defined as the total movement measured at the surface divided by the height of the slope failure. The limiting strain for most toppling and rock mass failure mode cases was found to be less than about $4 \%$. On November 1 , 2016 , the strain for the Main Instability Zone was approximately $0.5 \%$. The strain increased to approximately $2 \%$ by January 1, 2017 and reached approximately $4 \%$ by mid-February 2017. Although the Southwest Wall instability did not 'collapse', the exceedance of $4 \%$ strain coincided closely with acceleration in slope movement observed in early February 2017. Interestingly this is approximately when the Key Block began to show early signs of accelerating and yielding.

\subsection{Instability management and Safe Work Plan}

A SWP outlining the monitoring plan and associated trigger-action-response plan (TARP) was developed for operating in the bottom of Granite Pit in the vicinity of the Southwest Wall instability. The SWP was continuously evaluated and adjusted, where appropriate (mainly by bench), as mining progressed in the area 
of the instability. The primary monitoring tool was the SSR. Displacement rate thresholds were established for three exclusion zones in the pit bottom, as illustrated in Figure 7:

- Zone 1 is at the toe of the instability within the area for potential rockfall. Mining operations in Zone 1 are permitted if the displacement rates are below $400 \mathrm{~mm} /$ day.

- Zone 2 is within the interpreted runout area of the instability. Mining operations in Zone 2 are permitted if the displacement rates are below $700 \mathrm{~mm} /$ day.

- Zone 3 is outside the interpreted runout area of the instability. Mining operations in Zone 3 are permitted if the displacement rates are below 1,000 mm/day. Zone 3 was located outside the interpreted runout zone but includes an area requiring access for pit dewatering.

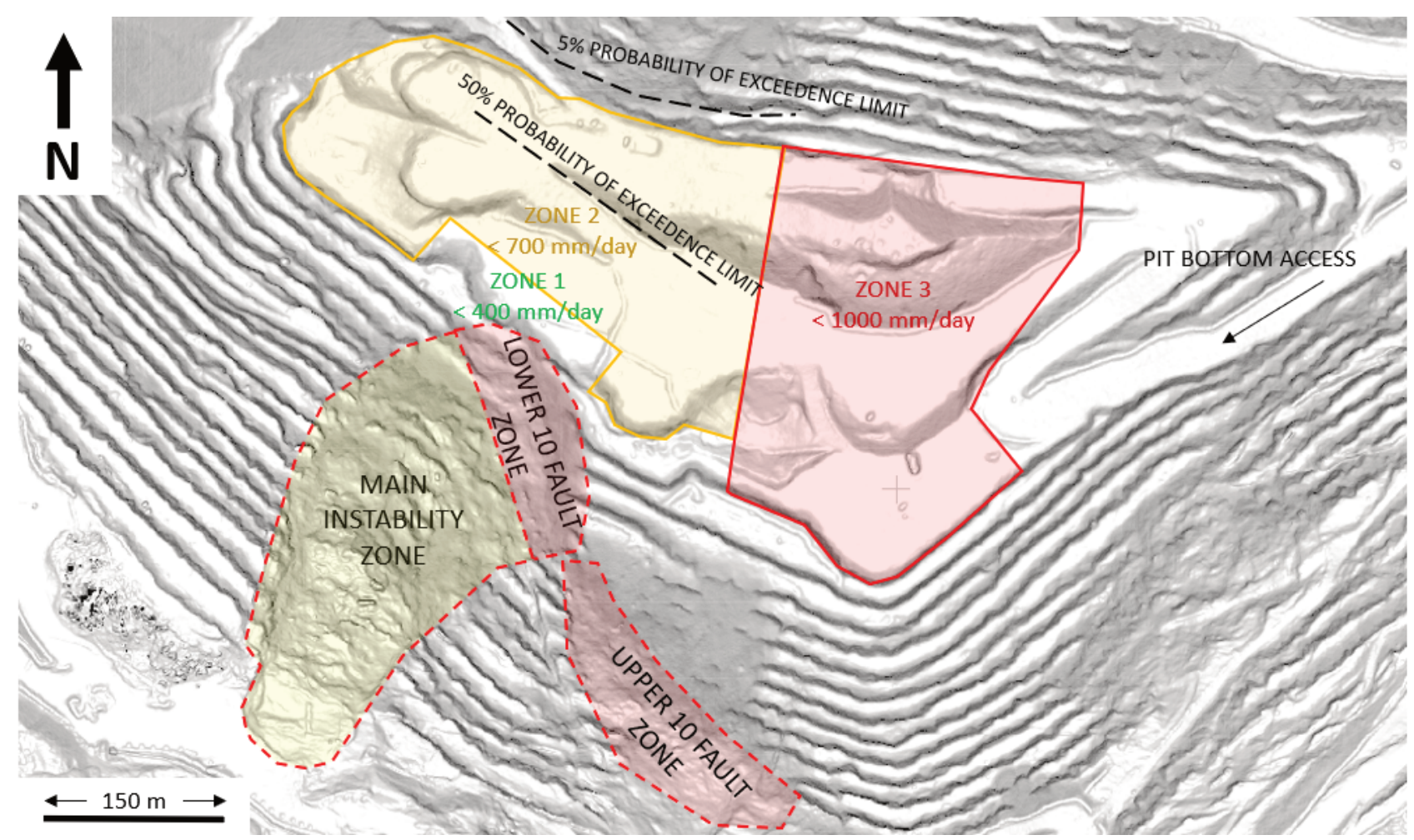

Figure 7 Granite Pit safe operating areas and estimated runout limits overlain on the May 1, 2017 unmanned aerial vehicle digital terrain model

The geotechnical engineering team developed the deformation rate thresholds for the three exclusion zones with input from the GroundProbe SSR. The thresholds were informed by previous deformation rates experienced by the Southwest Wall instability, and deformation rates experienced from previous slope instabilities in the Granite Pit, particularly the instability on the Southwest Wall in Phase 4. The deformation rate trends were also reviewed for acceleration/deceleration of the instability to inform when digging and access was permitted.

The potential runout distance for the Main Instability Zone was estimated using the methodology proposed by Whittall et al. (2016). The estimated runout angles for a $50 \%$ and $5 \%$ probably of exceedance was found to be $28^{\circ}$ and $21^{\circ}$, which corresponds to a runout length of approximately $180 \mathrm{~m}$ and $270 \mathrm{~m}$ from the toe of the slope, respectively. The estimated runout limits are shown in Figure 7.

Figure 8 shows the deformation rate trends for the most active period of the instability, between March 1, 2017 and June 15, 2017. As mining at the toe of the El. $975 \mathrm{~m}$ bench and exposure of 10 Fault progressed, so did the time it takes for the deformation rates to decay below the safe operating thresholds following mine events. 


\begin{tabular}{llll}
\hline & UPPER SLOPE & LOWER 10 FAULT \\
\cline { 3 - 3 } & BLAST EVENT (G5 SOUTHWEST) & $\star$ & BLAST EVENT (GRANITE PIT)
\end{tabular}

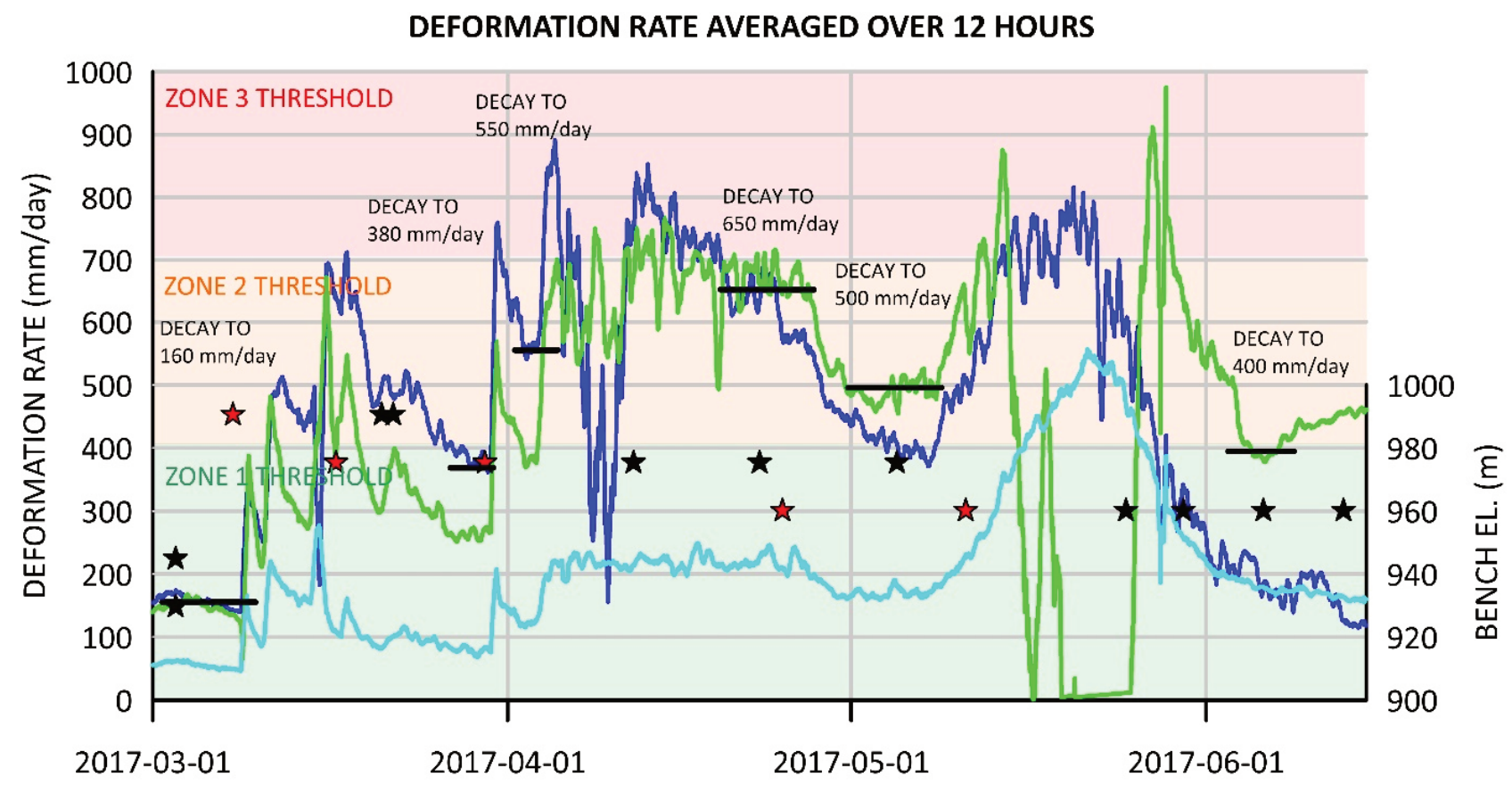

Figure 8 Slope stability radar deformation rate trends between March 1, 2017 and June 15, 2017

\subsection{Successful mining to the Final Pit Bottom}

Deformations in the weak rock within the Upper 10 Fault Zone resulted in sloughing of fault material and generation of rockfalls. Accumulation of rockfall debris on the benches below resulted in a loss of catchment. To mitigate the potential for rockfalls to impact the working benches below, a $30 \mathrm{~m}$ wide step-in with a $4.5 \mathrm{~m}$ high impact berm was implemented on the El. $1006 \mathrm{~m}$ bench (Figures 2 and 9). A $75 \mathrm{~m}$ wide step-in was also implemented at the El. $975 \mathrm{~m}$ bench (Figure 9). The purpose of the wider step-in was to provide a buttress for the slope below the Key Block where 10 Fault was projected to daylight, as well as to provide catchment for rockfalls and ravelling materials from the Main Instability and the Lower 10 Fault Zones. As shown in Figure 9, 10 Fault was daylighted through the buttress rather than further west along the slope below the Key Block where it was originally anticipated.

From about mid-May to the end of August 2017, only a limited amount of mining occurred in the pit bottom. Initially, this was due to delays incurred while waiting for the slope deformation rates to subside. Later, starting in early July 2017, the entire region surrounding the mine was experiencing forest fires, and production at the mine was temporarily stopped. The limited mining at the toe of the instability during this period, along with likely seasonal decreases in the pore pressures in the slope, appears to have allowed the instability time to stabilise. When mining resumed in September 2017, there were minimal production stoppages due to deformation rates exceeding the SWP thresholds.

Sixteen (16) HDHs were drilled into the Southwest Wall in 2017 between the El. $1021 \mathrm{~m}$ (drilled in January 2017) and El. $945 \mathrm{~m}$ (drilled in August and September 2017) benches with lengths varying between $100 \mathrm{~m}$ and $300 \mathrm{~m}$. HDHs were implemented as historical VWP data in the Southwest Wall showed only a limited amount of passive depressurisation of the slope due to mining. The $\mathrm{HDH}$ traces and observed flow rates along the drillhole are shown in Figure 9. The main targets for $\mathrm{HDH}$ s were major geological structures (i.e. faults) as they have typically acted as groundwater water barriers. Increases in HDH groundwater flow rates were observed at the projected interpretations of 8 Fault, 9 Fault, and NF6 Fault boundaries confirming that these 
faults act as barriers. Eleven (11) of the HDHs produced water, with a maximum observed flow rate of $1,200 \mathrm{~L} / \mathrm{min}$ when the interpreted 8 Fault boundary was intersected.
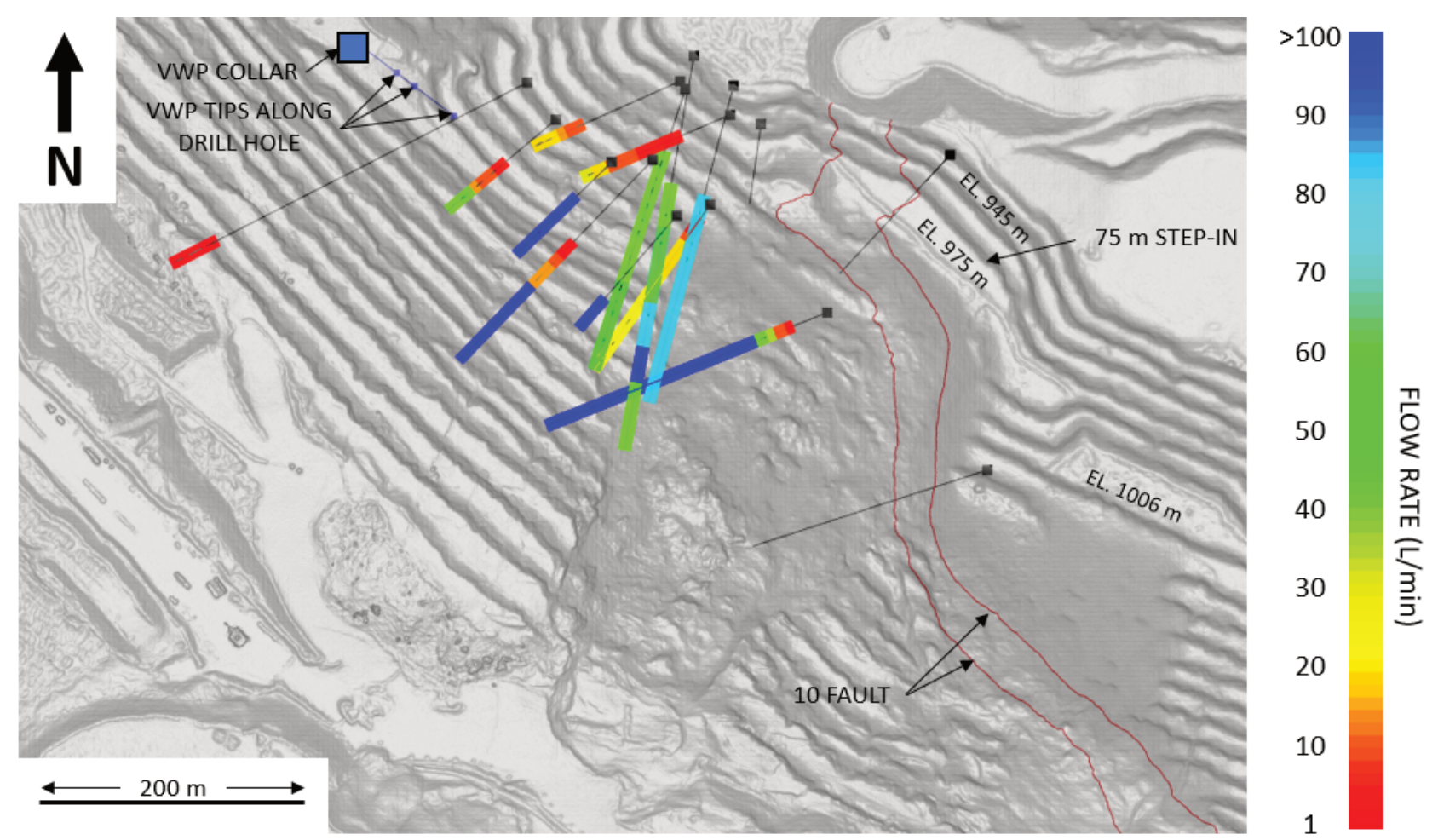

Figure 9 Horizontal drain holes locations and observed flow rates along the drillhole trace overlain on the December 1, 2017 unmanned aerial vehicle digital terrain model

A nest of three VWPs was installed in May 2017, as shown in Figure 9. Figure 10 shows the hydrographs for the three VWPs with the timing of the HDH drilling program. The middle and deep VWP show an overall decrease in hydraulic head, possibly affected by the HDHs but more likely due to passive drainage associated with mining as the distance from the drain holes to the piezometers was high. An increase in hydraulic head was observed in the middle and shallow VWPs mid-October 2017, considered likely in response to rainfall events. The deep VWP was installed below 10 Fault and does not show a similar response as the middle and upper VWPs. Groundwater seepage has been observed in the pit walls below the footwall of 10 Fault, providing further evidence that 10 Fault is a boundary between groundwater regimes.

It remains unclear if the reduced slope movement displacement rates were due to the step-in at the El. $975 \mathrm{~m}$ bench, the cessation of mining, the dry weather conditions or the reduction in porewater pressures due to the HDHs. By December 1, 2017, the instability was $265 \mathrm{~m}$ high, came to rest at an overall slope angle of $30^{\circ}$, and experienced approximately $26 \%$ strain, well exceeding the typical upper bound for toppling and rock mass failures. As of October 2019, the lower benches of the Main Instability have been buttressed by an in-pit dump. The Upper 10 Fault Zone, however, continues to ravel and slowly deform at approximately $25 \mathrm{~mm} /$ day. 


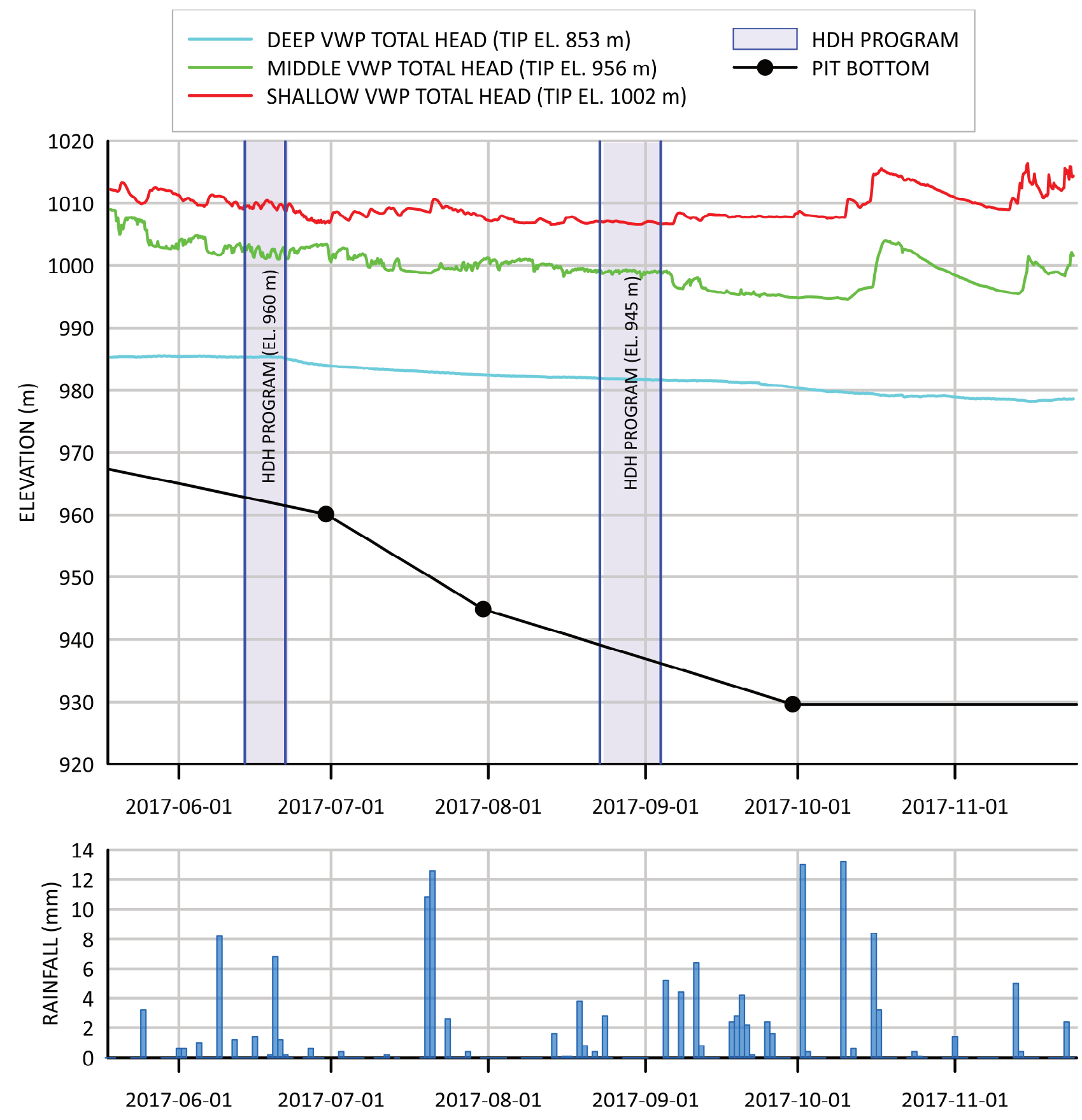

Figure 10 Hydrograph and rainfall measurements for the nested vibrating wire piezometers in the Southwest Wall

\section{Conclusion}

An instability database was presented showing slope height and slope angle relationships for 26 cases of instability at a large open pit copper mine in British Columbia. The instability database has been used to inform pit slope designs in areas where specific major geological structures are expected to occur. Identification of potential complex failure mechanisms is the key to successful pit slope designs and management of potentially high slope movements, and depends on the ability to identify, map, and model major structures.

A slope instability that developed in the Phase 5 Southwest Wall of the Granite Pit that was successfully managed to the ultimate pit bottom was presented. Data from multiple monitoring systems were used to understand the complex failure mechanism and was a key component of the instability management 
strategy. Three exclusion zones were defined as part of the SWP based on runout estimates and historical displacement rates recorded by the SSR. The largest deformation rates tended to occur when 10 Fault was exposed on successive benches. The highly disturbed rock mass within the 10 Fault zone is interpreted to be squeezing and shearing, possibly providing a basal shear plane for the toppling instability. Longer periods of time were required to before slope deformation rates were less than the established thresholds until mining progressed below 10 Fault.

A $75 \mathrm{~m}$ wide step-in was implemented at the El. $975 \mathrm{~m}$ bench to provide a buttress for the slope below the Key Block where 10 Fault was projected to daylight, as well as to provide catchment for rockfalls and ravelling from the Main Instability and the Lower 10 Fault Zones. This buttress functioned as-designed, and the failure did not propagate below the buttress.

Based on the groundwater flow rates measured in the $\mathrm{HDHs}$, groundwater was likely a factor in the instability but confirming this was difficult due to compartmentalisation of the groundwater between major geologic structures. The slope was successfully mined to El. $930 \mathrm{~m}$, one bench shy of the ultimate depth. It remains unclear if the reduced slope movement displacement rates were due to the step-in at the El. $975 \mathrm{~m}$ bench, the mining hiatus due to events that were not in control of the mine, climatic conditions or reduced porewater pressures from the installation of the HDHs.

\section{References}

Danielson, J, Stead, D, Kinakin, D \& Smith, S 2017, 'The use of specific energy for fault mapping in an open pit mine', Proceedings of the 51st US Rock Mechanics/Geomechanics Symposium 2017, American Rock Mechanics Association, Alexandria, pp. 815-821.

Danielson, J 2018, An Investigation into the Time Dependent Deformation Behaviour of Open Pit Slopes at Gibraltar Mine, BC, Canada, MSc thesis, Simon Fraser University, Burnaby.

Dick, GJ, Eberhardt, E, Cabrejo-Liévano, AG, Stead, D \& Rose, ND 2015, 'Development of an early-warning time-of-failure analysis methodology for open-pit mine slopes utilizing ground-based slope stability radar monitoring data', Canadian Geotechnical Journal, vol. 52, pp. 515-529.

Hungr, O, Leroueil, S \& Picarelli, L 2014, 'The Varnes classification of landslide types, an update', Landslides, vol. 11, pp. 167-194.

Mercer, KG 2006, Investigation into the Time Dependent Deformation Behaviour and Failure Mechanisms of Unsupported Rock Slopes Based on the Interpretation of Observed Deformation Behaviour, PhD thesis, University of the Witwatersrand, Johannesburg.

Mostaghimi, N \& Kennedy, L 2015, 'Structural geology of the Granite Lake pit, Gibraltar copper-molybdenum mine, south-central British Columbia (NTS 093B/08,/09): preliminary observations', Geoscience BC Summary of Activities 2014, Report 2015-1, pp. 129-140.

Newcomen, HW \& Dick, GJ 2015, 'An update to strain-based pit wall failure prediction method and a justification for slope monitoring', 2015 Proceedings of the International Symposium on Slope Stability in Open Pit Mining and Civil Engineering Slope Stability, South African Institute of Mining and Metallurgy, Johannesburg, pp. 139-150.

Nunoo, S, Tannant, DD \& Newcomen, HW 2015, 'Slope monitoring practices at open pit porphyry mines in British Columbia, Canada', International Journal of Mining, Reclamation and Environment, vol. 30, iss. 3, pp. 245-256.

Sjöberg, J 2000, 'A slope height versus slope angle database', Slope Stability in Surface Mining, Society for Mining, Metallurgy, and Exploration (SME), Littleton.

Whittall, J, Eberhardt, E \& McDougall, S 2016, 'Runout analysis and mobility observations for large open pit slope failures', Canadian Geotechnical Journal, vol. 54, pp. 373-391. 
